Neurosurg Focus 18 (3):E9, 2005

\title{
Kyphoplasty-augmented short-segment pedicle screw fixation of traumatic lumbar burst fractures: initial clinical experience and literature review
}

\author{
Frank L. Acosta Jr., M.D., Henry E. Aryan, M.D., William R. Taylor, M.D., \\ AND Christopher P. AMES, M.D. \\ Department of Neurological Surgery, University of California, San Francisco; \\ and California Department of Neurological Surgery, University of California San Diego, California
}

\begin{abstract}
Object. Surgical intervention for thoracolumbar burst fractures is indicated for patients with neurological deficits and/or evidence of severe spinal instability. The goals of surgery are decompression, deformity correction, and stabilization. Nevertheless, the optimal surgical strategy to achieve these goals remains a subject of debate. Short-segment pedicle screw fixation is associated with a 20 to $50 \%$ incidence of pedicle screw failure and progressive spinal deformity. Initial biomechanical and clinical studies have shown that reinforcement of short-segment pedicle screw fixation with vertebroplasty improves spinal stability and decreases instrument failure rates. In this study, the authors describe their initial clinical experience with kyphoplasty used to augment short-segment pedicle screw fixation of traumatic lumbar burst fractures.

Methods. Five patients with traumatic burst fractures of the lumbar spine were included in this retrospective review of patients treated for this disorder at the University of California, San Diego and the University of California, San Francisco between 2002 and 2004. All patients underwent transpedicular kyphoplasty and short-segment pedicle screw fixation. The mean follow-up period was 10.6 months (range 6-18 months). All patients underwent short-segment pedicle screw fixation reinforced with polymethyl methacrylate kyphoplasty. The preoperative, postoperative, and follow-up plain x-ray films were evaluated. Radiographic analysis included measurements of kyphotic angulation, anterior vertebral body height, and evidence of bone fusion. Clinical evaluation was performed postoperatively and at follow-up review.

Conclusions. Based on the authors' initial experience, kyphoplasty supplementation may improve the long-term integrity of short-segment pedicle screw constructs and allow for improved rates of fusion and better clinical outcomes in patients with traumatic lumbar burst fractures.
\end{abstract}

KEY WORDS - burst fracture • lumbar spine • kyphoplasty • pedicle screw fixation

The optimal treatment of burst fractures of the thoracolumbar spine remains a matter of debate. Traditionally, nonsurgical management with immobilization and external bracing has been recommended for patients with burst fractures located between T-11 and L-4 without accompanying neurological deficit or significant instability. $11,27,45$ Progressive deformity, neurological dysfunction, and pain are common in cases treated without surgical stabilization, however, and some authors have criticized treatment that does not include surgical decompression and stabilization. ${ }^{18}$ Although Class 1 data are lacking, surgical treatment of thoracolumbar burst fractures has been recommended for patients with neurological deficit or severe instability (that is, posterior element fractures, kyphotic deformity $\geq 20^{\circ}$, and $>50 \%$ loss of VB height with facet joint subluxation). $)^{2,16,23,24,29,36}$

Abbreviations used in this paper: PMMA = polymethyl methacrylate; $\mathrm{VB}=$ vertebral body.
Short-segment pedicle screw fixation is a common and relatively simple method for treating thoracolumbar burst fractures, and potentially allows for spinal stabilization while preserving as many motion segments as possible. ${ }^{8,25}$. 27,37,43,44 Nevertheless, instrument failure rates and progressive sagittal deformity have been reported in as many as $50 \%$ of patients treated with short-segment pedicle screw fixation alone. ${ }^{32,38}$ Patients with failed constructs in whom progressive kyphosis subsequently develops have poorer functional outcomes, higher analgesic medication requirements for back pain, and may ultimately require a second procedure for instrumentation removal., ${ }^{7,10,31}$

Cement vertebroplasty has been shown to increase the strength, load-bearing capacity, and stiffness of fractured vertebrae. ${ }^{5,9,17} \mathrm{We}$ believe that the addition of a balloon tamp (kyphoplasty) to the traditional vertebroplasty procedure may provide additional vertebral height restoration and stability. In this study, we review our initial clinical experience with kyphoplasty in which we used PMMA 
cement to supplement short-segment pedicle screw fixation for traumatic lumbar burst fractures. We also describe the current biomechanical rationale for and clinical experience with vertebroplasty and kyphoplasty to augment short-segment posterior pedicle screw-rod constructs for thoracolumbar burst fractures.

\section{CLINICAL MATERIAL AND METHODS}

\section{Patient Population}

We retrospectively evaluated the results in five patients with traumatic burst fractures of the lumbar spine that were treated at our institutions with transpedicular kyphoplasty and short-segment pedicle screw fixation. The patients' mean age at the time of surgery was 53 years (range 42-68 years). Indications for surgical intervention were the presence of neurological deficit, severe spinal instability (loss of anterior VB height $>50 \%$, canal compromise $>50 \%$, or kyphotic deformity $>20^{\circ}$ ), or intractable back pain. The patients' demographic data are shown in Table 1. Four patients suffered burst fractures as a result of falls, whereas one had been in a motor vehicle accident. All patients had a single-level Type $\mathrm{A} 1^{3}$ vertebral fracture (vertebral collapse with retropulsion of the posterior vertebral wall), according to the classification proposed by Magerl, et al. ${ }^{35}$ The mean follow-up period was 10.6 months (range 6-18 months).

\section{Surgical Methods}

All patients underwent surgical intervention via a posterior approach. Bilateral pedicle screws were inserted at one level above and below the fractured VB. Under fluoroscopic guidance, a kyphoplasty trochar was introduced along the pedicle of the fractured VB and was placed just beyond the posterior vertebral wall. A kyphoplasty balloon was then advanced into the VB and slowly inflated to $150 \mathrm{psi}$. This allowed for both fracture reduction and vertebral height restoration. The balloon was then deflated and removed and the cavity was filled with 3 to $10 \mathrm{~cm}^{3}$ of barium-impregnated PMMA cement. Any extruded PMMA was promptly removed with pituitary rongeurs.

A laminectomy was then performed at the fractured level for spinal canal decompression. The ventral thecal sac was decompressed using pituitary rongeurs and downpushing curettes were used to remove extruded bone fragments. Rods were then fashioned and secured to the pedicle screws bilaterally. Finally, a distraction force was applied to the pedicle screws bilaterally across the frac-

\section{TABLE 1}

Demographic data in five patients treated for traumatic burst fractures*

\begin{tabular}{ccclc}
\hline \hline Case No. & Age (yrs), Sex & Fx Level & Presenting Symptoms & FU (mos) \\
\hline 1 & $44, \mathrm{~F}$ & L-4 & back pain & 6 \\
2 & $42, \mathrm{M}$ & L-2 & back pain, neuro deficit & 7 \\
3 & $68, \mathrm{M}$ & L-2 & back pain & 9 \\
4 & $58, \mathrm{M}$ & L-1 & back pain & 18 \\
5 & $45, \mathrm{~F}$ & L-3 & back pain, neuro deficit & 13 \\
\hline
\end{tabular}

$* \mathrm{FU}=$ follow up; $\mathrm{fx}=$ fracture; neuro $=$ neurological. tured VB to achieve spinal reduction, and the screw-rod construct was tightened.

\section{Radiographic Evaluation}

The preoperative, postoperative, and follow-up plain xray films were evaluated. Radiographic analysis included measurements of kyphotic angulation, anterior VB height, and evidence of bone fusion. Local kyphosis was measured using the Cobb method, as described in Kuner, et al. ${ }^{33}$ Anterior VB height was measured directly, and the percentage change in height was calculated by dividing the actual anterior VB height by the estimated normal height (defined as the mean of the anterior VB height of the uninjured adjacent vertebrae above and below). Evidence of bone fusion included the presence of trabecular bone bridging the interspace between the cement and adjacent VB, with no areas of increased lucency.

\section{Clinical Evaluation}

The clinical evaluation was performed postoperatively and at follow-up review. It included a thorough neurological examination and a questionnaire on the patients' perceived pain level based on the visual analog scale.

\section{RESULTS}

All patients had suffered fractures of the lumbar spine. Table 2 provides a summary of the radiographic results in this study. The mean preoperative kyphotic deformity was $36 \pm 3.74^{\circ}$ (all values are the mean \pm standard deviation) and was corrected to $5 \pm 6.12^{\circ}(\mathrm{p}<0.01)$. The mean loss of correction of local kyphosis at follow-up review was $4 \pm 4.18^{\circ}(\mathrm{p}>0.05)$. The mean preoperative anterior height of the fractured VB was $54 \pm 4.12 \%$. Postoperatively, this improved to $86 \pm 8.22 \%$, a $32 \%$ increase in height $(\mathrm{p}<0.01)$. Anterior VB height was not significantly changed at follow-up review. The preoperative, postoperative, and follow-up changes in kyphosis and vertebral height are summarized in Fig. 1. All patients had radiographic evidence of fusion, improved neurological deficits, and improved pain scores. There was no hardware failure or leakage of PMMA cement in any patient. The preoperative, intraoperative, and postoperative radiographic images obtained in a patient treated with PMMA vertebroplasty are shown in Fig. 2.

\section{DISCUSSION}

As shown in Table 3, the following three major ap-

TABLE 2

Radiographic results in five patients with burst fractures

\begin{tabular}{|c|c|c|c|c|c|c|c|c|}
\hline \multirow[b]{2}{*}{$\begin{array}{l}\text { Case } \\
\text { No. }\end{array}$} & \multicolumn{4}{|c|}{ Kyphosis $\left({ }^{\circ}\right)$} & \multicolumn{4}{|c|}{ Anterior VB Height (\%) } \\
\hline & Preop & Postop & FU & $\begin{array}{c}\% \text { Correction } \\
\text { Loss }\end{array}$ & Preop & Postop & FU & $\begin{array}{c}\text { Height } \\
\text { Loss }\end{array}$ \\
\hline 1 & 30 & 5 & 10 & 5 & 60 & 90 & 80 & 10 \\
\hline 2 & 40 & 15 & 15 & 0 & 50 & 75 & 75 & 0 \\
\hline 3 & 40 & 0 & 10 & 10 & 50 & 80 & 75 & 5 \\
\hline 4 & 35 & 5 & 5 & 0 & 55 & 90 & 80 & 10 \\
\hline 5 & 35 & 0 & 5 & 5 & 55 & 95 & 90 & 5 \\
\hline mean & 36 & 5 & 9 & 4 & 54 & 86 & 80 & 6 \\
\hline
\end{tabular}




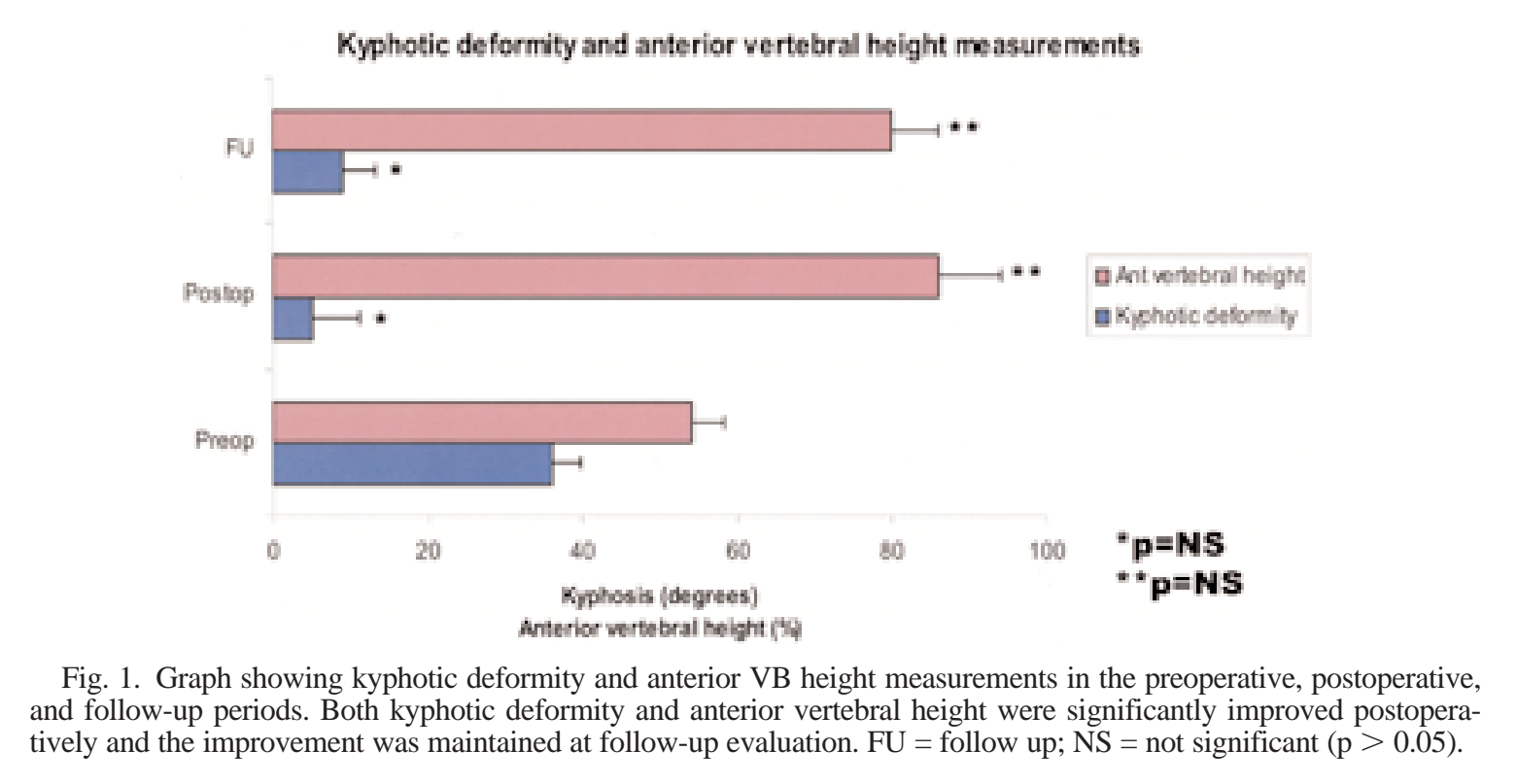

proaches have been used in the surgical treatment of thoracolumbar burst fractures. 1) Anterior approaches have proven effective in allowing for extensive decompression and successful fusion with minimal loss of sagittal alignment, ${ }^{4,26,29}$ but the time needed and morbidity rates associated with an anterior spinal exposure are both higher than with posterior approaches..$^{29}$ 2) Posterior approaches with short-segment pedicle screw fixation allow for adequate realignment and stabilization, but are associated with high rates of instrument failure because the anterior and middle columns are not reconstructed. ${ }^{3,38}$ Moreover, intervertebral disc material is redistributed into the fractured VB after height restoration, causing a subsequent collapse of adjacent disc spaces and leading to instrument fatigue and progressive kyphosis. ${ }^{42,51}$ Extension of the posterior pedicle screw-rod construct to include two or more segments above and below the fractured level can reduce instrument failure rates, but it also sacrifices additional motion segments and ultimately reduces the range of motion. ${ }^{13} 3$ ) Combined anterior-posterior approaches allow for threecolumn reconstruction and stabilization, ${ }^{21}$ but also require more time and have higher rates of surgery-related morbidity.

An ideal technique would combine the stability offered by three-column reconstruction with the morbidity level associated with a single short-segment posterior approach only. Accordingly, transpedicular bone grafts have been used to provide additional anterior column support after short-segment posterior transpedicular screw fixation, but with mixed results. ${ }^{1,15,41,47}$ In a recent prospective, randomized study, Alanay, et al., ${ }^{2}$ found no difference in the failure rates of short-segment pedicle screw constructs supplemented with transpedicular intracorporeal bone graft compared with constructs without graft support. Moreover, transpedicular graft material can cause spinal canal compression if not placed properly. ${ }^{46}$ The injection of cement into the anterior column (vertebroplasty) with or without an inflatable bone tamp (kyphoplasty) is another procedure that provides additional anterior support via a posterior approach for pedicle screw fixation. Vertebro- plasty and kyphoplasty have been found to be effective in the treatment of osteoporotic compression fractures, ${ }^{14,19,28}$ and there is growing evidence that these methods may also be useful in improving instrumentation failure rates and deformity correction after posterior fixation in patients with thoracolumbar burst fractures.

\section{Biomechanical Effects of Vertebroplasty and Kyphoplasty}

The restoration of VB strength and stiffness is thought to be an important part of the mechanism by which vertebroplasty and kyphoplasty may relieve pain associated with fractured vertebrae. ${ }^{9,50}$ The use of PMMA cement has been shown to restore vertebral strength and stiffness in relation to the volume of cement injected, although complete filling of the VB is not necessary. ${ }^{50} \mathrm{It}$ is hypothesized that this increase in VB strength and stiffness may also result in a shift of loading forces onto the anterior column, thus decreasing the tensile forces on posterior instrumentation. ${ }^{40}$

The use of inflatable bone tamps in kyphoplasty may provide additional restoration of VB height. In several studies, investigators have reported that kyphoplasty improves both anterior and midline vertebral height from 91 to $99 \%$ of estimated prefracture values..$^{22,48,50}$ In research in which cadaveric spines were used, Belkoff, et al., ${ }^{6}$ reported that kyphoplasty resulted in a $97 \%$ correction of deformity, compared with $30 \%$ with vertebroplasty. Verlaan, et al. ${ }^{51}$ found that inflatable bone tamps facilitated endplate reduction and cement injection in a cadaveric study. Thus, by creating a void into which cement can be injected at low pressure, kyphoplasty may facilitate both vertebral height restoration and decrease the risk of cement leakage. ${ }^{51}$ In our series, we encountered no leakage of PMMA into the spinal canal.

\section{Results of Vertebroplasty-Augmented Posterior Pedicle Screw Fixation}

Progressive deformity, vertebral height loss, and implant failure occur with certainty after short-segment pedi- 

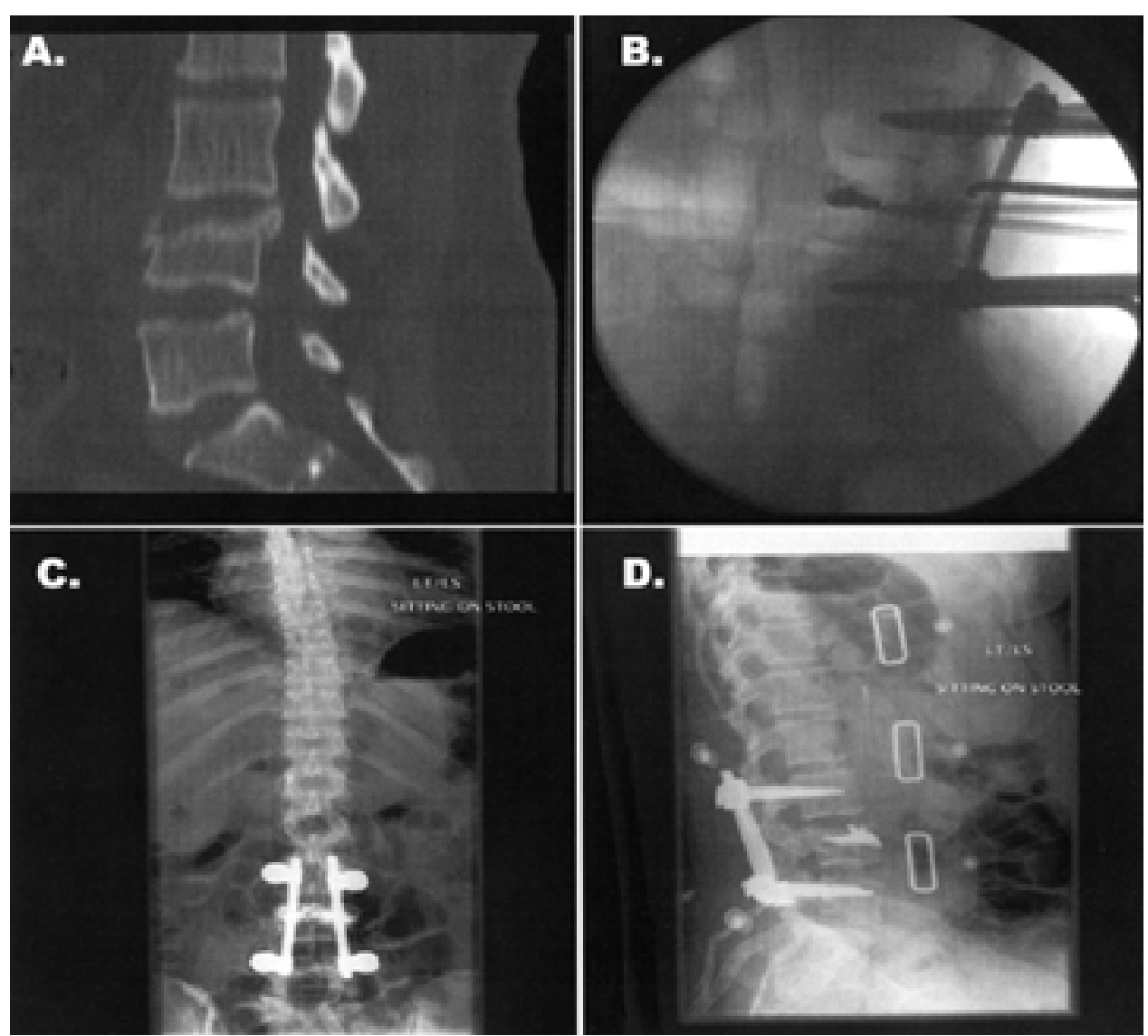

Fig. 2. Radiographs obtained in a patient with an L-4 burst fracture. A: Preoperative sagittal computerized tomographic reconstruction demonstrating a burst fracture of the L-4 VB. B: Intraoperative fluoroscopic image demonstrating injection of PMMA cement into the L-4 body during kyphoplasty. C and D: Postoperative anteroposterior (C) and lateral (D) plain x-ray films demonstrating pedicle screw-rod fixation at one level above and below the fractured vertebrae and PMMA cement within the L-4 body.

cle screw fixation of thoracolumbar burst fractures. As much as 50 to $90 \%$ of kyphosis correction has been reported lost at follow-up evaluation. ${ }^{12,34}$ McNamara, et al., ${ }^{39}$ reported a mean loss of $8.6^{\circ}$ of kyphosis correction, whereas Cho, et al., ${ }^{13}$ found that $6.2^{\circ}$ of kyphosis correction was lost in patients treated with short-segment fixation alone. Loss of VB height ranges from 11 to $14 \%,,^{13,31}$ whereas 20 to $50 \%$ of patients experience implant failure. ${ }^{7,32,38}$ Chronic

TABLE 3

Summary of surgical options for thoracolumbar burst fractures

\begin{tabular}{lll}
\hline \hline Approach & \multicolumn{1}{c}{ Advantages } & Disadvantages \\
\hline anterior & extensive decompression & high morbidity level \\
& successful fusion & no posterior column \\
& restoration of anterior & fixation \\
& VB height & \\
& limited exposure & \\
& low morbidity & no anterior or middle \\
posterior & 3-column fixation & column reconstruction \\
& w/ pedicle screws & significant instrument \\
& & failure rates \\
& & significant morbidity w/ \\
combined & 3-column fixation \& & combined exposure \\
& reconstruction &
\end{tabular}

and severe pain necessitate a second operation for removal of failed implants in as many as $10 \%$ of patients. ${ }^{12,40}$

To our knowledge, the actual clinical experience with vertebroplasty and short-segment fixation is extremely limited. In a recent study in which they compared shortsegment pedicle screw fixation with or without PMMA vertebroplasty for thoracolumbar burst fractures, Cho, et al. ${ }^{13}$ found that the amount of kyphosis correction lost at follow-up review was $6.20^{\circ}$ in the group without vertebroplasty compared with $0.33^{\circ}$ in the group with reinforced fixation $(\mathrm{p}=0.0001)$. There were no instrument failures in the vertebroplasty group, whereas $22 \%$ failed in the group without reinforcement. Fusion rates were not reported. The results of this study indicate that vertebroplasty can maintain kyphosis correction and anterior vertebral height, and can decrease instrument failure rates after short-segment posterior fixation for thoracolumbar burst fractures. ${ }^{13}$

We hypothesized that the use of a bone tamp to provide a distractive force within the VB during kyphoplasty may result in additional kyphosis correction and anterior VB height restoration. We were able to achieve a $31^{\circ}$ correction of kyphosis after surgery and restore $32 \%$ of the anterior vertebral height. Cho, et al., ${ }^{13}$ reported a mean of $6.4^{\circ}$ of kyphosis correction and $12.9 \%$ anterior VB height res- 
toration after vertebroplasty and short-segment fixation. Although our patients had a greater preoperative anterior vertebral height (54\% compared with $45 \%$ ), they also had a larger preoperative kyphotic deformity $\left(36^{\circ}\right.$ compared with $20^{\circ}$ ) than the patients reported on by Cho, et al. ${ }^{13} \mathrm{We}$ found no significant loss of kyphosis correction or anterior vertebral height at follow-up review. Moreover, all patients demonstrated radiographic evidence of fusion.

\section{Future Directions}

Large, randomized prospective studies are needed to evaluate fully the efficacy of vertebroplasty and kyphoplasty for augmentation of short-segment pedicle screw constructs in the treatment of thoracolumbar burst fractures. Additionally, cements other than PMMA should be incorporated into these studies. Injury to spinal tissues is one concern when using PMMA; this material can have toxic effects as a monomer, and may also cause thermal injury during its exothermic polymerization reaction..$^{9,20,30}$ Thus, more biocompatible and, ideally, osteoconductive (calcium-phosphate) cements are being studied. In a biomechanical study of compression fractures in cadavers, Tomita, et al. ${ }^{49}$ found that there was no difference in percentage of VB height restoration or strength restoration after PMMA kyphoplasty compared with a calcium-phosphate cement kyphoplasty.

\section{CONCLUSIONS}

Vertebroplasty decreases instrument failure rates after short-segment pedicle fixation for thoracolumbar burst fractures. Based on our initial experience with only a small number of patients, use of inflatable bone tamps with kyphoplasty may provide additional kyphosis correction, vertebral height restoration, and long-term integrity of short-segment pedicle screw constructs. This may ultimately result in improved rates of fusion and better clinical outcomes for patients with traumatic lumbar burst fractures. Large, prospective studies are needed to evaluate fully the efficacy of vertebroplasty and kyphoplasty in augmenting short-segment pedicle screw fixation for thoracolumbar burst fractures.

\section{References}

1. Aebi M, Etter C, Kehl T, et al: Stabilization of the lower thoracic and lumbar spine with the internal spinal skeletal fixation system. Indications, techniques, and first results of treatment. Spine 12:544-551, 1987

2. Alanay A, Acaroglu E, Yazici M, et al: Short-segment pedicle instrumentation of thoracolumbar burst fractures: does transpedicular intracorporeal grafting prevent early failure? Spine 26: 213-217, 2001

3. Alvine GF, Swain JM, Asher MA, et al: Treatment of thoracolumbar burst fractures with variable screw placement or Isola instrumentation and arthrodesis: case series and literature review. J Spinal Disord Tech 17:251-264, 2004

4. Been HD: Anterior decompression and stabilization of thoracolumbar burst fractures by the use of the Slot-Zielke device. Spine 16:70-77, 1991

5. Belkoff SM, Mathis JM, Erbe EM, et al: Biomechanical evaluation of a new bone cement for use in vertebroplasty. Spine 25: 1061-1064, 2000
6. Belkoff SM, Mathis JM, Fenton DC, et al: An ex vivo biomechanical evaluation of an inflatable bone tamp used in the treatment of compression fracture. Spine 26:151-156, 2001

7. Benson DR: Unstable thoracolumbar fractures, with emphasis on the burst fracture. Clin Orthop 230:14-29, 1988

8. Boriani S, Palmisani M, Donati U, et al: The treatment of thoracic and lumbar spine fractures: a study of 123 cases treated surgically in 101 patients. Chir Organi Mov 85:137-149, 2000

9. Bostrom MP, Lane JM: Future directions. Augmentation of osteoporotic vertebral bodies. Spine 22 (Suppl 24):38S-42S, 1997

10. Boucher M, Bhandari M, Kwok D: Health-related quality of life after short segment instrumentation of lumbar burst fractures. J Spinal Disord 14:417-426, 2001

11. Cantor JB, Lebwohl NH, Garvey T, et al: Nonoperative management of stable thoracolumbar burst fractures with early ambulation and bracing. Spine 18:971-976, 1993

12. Carl AL, Tromanhauser SG, Roger DJ: Pedicle screw instrumentation for thoracolumbar burst fractures and fracture-dislocations. Spine 17 (Suppl 8):S317-S324, 1992

13. Cho DY, Lee WY, Sheu PC: Treatment of thoracolumbar burst fractures with polymethyl methacrylate vertebroplasty and short-segment pedicle screw fixation. Neurosurgery 53: 1354-1361, 2003

14. Cortet B, Cotten A, Boutry N, et al: Percutaneous vertebroplasty in the treatment of osteoporotic vertebral compression fractures: an open prospective study. J Rheumatol 26:2222-2228, 1999

15. Crawford RJ, Askin GN: Fixation of thoracolumbar fractures with the Dick fixator: the influence of transpedicular bone grafting. Eur Spine J 3:45-51, 1994

16. Danisa OA, Shaffrey CI, Jane JA, et al: Surgical approaches for the correction of unstable thoracolumbar burst fractures: a retrospective analysis of treatment outcomes. J Neurosurg 83: 977-983, 1995

17. Dean JR, Ison KT, Gishen P: The strengthening effect of percutaneous vertebroplasty. Clin Radiol 55:471-476, 2000

18. Denis F: The three column spine and its significance in the classification of acute thoracolumbar spinal injuries. Spine 8: 817-831, 1983

19. Deramond H, Depriester C, Galibert P, et al: Percutaneous vertebroplasty with polymethylmethacrylate. Technique, indications, and results. Radiol Clin North Am 36:533-546, 1998

20. Deramond H, Wright NT, Belkoff SM: Temperature elevation caused by bone cement polymerization during vertebroplasty. Bone 25 (Suppl 2):17S-21S, 1999

21. Dimar JR II, Wilde PH, Glassman SD, et al: Thoracolumbar burst fractures treated with combined anterior and posterior surgery. Am J Orthop 25:159-165, 1996

22. Garfin SR, Yuan HA, Reiley MA: New technologies in spine: kyphoplasty and vertebroplasty for the treatment of painful osteoporotic compression fractures. Spine 26:1511-1515, 2001

23. Gertzbein SD, Court-Brown CM, Jacobs RR, et al: Decompression and circumferential stabilization of unstable spinal fractures. Spine 13:892-895, 1988

24. Gertzbein SD, Court-Brown CM, Marks P, et al: The neurological outcome following surgery for spinal fractures. Spine 13: 641-644, 1988

25. Glaser JA, Estes WJ: Distal short segment fixation of thoracolumbar and lumbar injuries. Iowa Orthop J 18:87-90, 1998

26. Haas N, Blauth M, Tscherne H: Anterior plating in thoracolumbar spine injuries. Indication, technique, and results. Spine 16 (Suppl 3):S100-S111, 1991

27. Hitchon PW, Torner JC, Haddad SF, et al: Management options in thoracolumbar burst fractures. Surg Neurol 49:619-627, 1998

28. Jensen ME, Evans AJ, Mathis JM, et al: Percutaneous polymethylmethacrylate vertebroplasty in the treatment of osteo- 
porotic vertebral body compression fractures: technical aspects. AJNR 18:1897-1904, 1997

29. Kaneda K, Taneichi H, Abumi K, et al: Anterior decompression and stabilization with the Kaneda device for thoracolumbar burst fractures associated with neurological deficits. J Bone Joint Surg Am 79:69-83, 1997

30. Kirby BS, Doyle A, Gilula LA: Acute bronchospasm due to exposure to polymethylmethacrylate vapors during percutaneous vertebroplasty. AJR 180:543-544, 2003

31. Kramer DL, Rodgers WB, Mansfield FL: Transpedicular instrumentation and short-segment fusion of thoracolumbar fractures: a prospective study using a single instrumentation system. J Orthop Trauma 9:499-506, 1995

32. Kuklo TR, Polly DW, Owens BD, et al: Measurement of thoracic and lumbar fracture kyphosis: evaluation of intraobserver, interobserver, and technique variability. Spine 26:61-66, 2001

33. Kuner EH, Kuner A, Schlickewei W, et al: Ligamentotaxis with an internal spinal fixator for thoracolumbar fractures. J Bone Joint Surg Br 76:107-112, 1994

34. Louis CA, Gauthier VY, Louis RP: Posterior approach with Louis plates for fractures of the thoracolumbar and lumbar spine with and without neurologic deficits. Spine 23: 2030-2040, 1998

35. Magerl F, Aebi M, Gertzbein SD, et al: A comprehensive classification of thoracic and lumbar injuries. Eur Spine J 3: 184-201, 1994

36. McAfee PC, Yuan HA, Lasda NA: The unstable burst fracture. Spine 7:365-373, 1982

37. McLain RF, Burkus JK, Benson DR: Segmental instrumentation for thoracic and thoracolumbar fractures: prospective analysis of construct survival and five-year follow-up. Spine J 1: 310-323, 2001

38. McLain RF, Sparling E, Benson DR: Early failure of short-segment pedicle instrumentation for thoracolumbar fractures. A preliminary report. J Bone Joint Surg Am 75:162-167, 1993

39. McNamara MJ, Stephens GC, Spengler DM: Transpedicular short-segment fusions for treatment of lumbar burst fractures. J Spinal Disord 5:183-187, 1992

40. Mermelstein LE, McLain RF, Yerby SA: Reinforcement of thoracolumbar burst fractures with calcium phosphate cement. A biomechanical study. Spine 23:664-671, 1998

41. Olerud S, Karlstrom G, Sjostrom L: Transpedicular fixation of thoracolumbar vertebral fractures. Clin Orthop 227:44-51, 1988
42. Oner FC, van der Rijt RR, Ramos LM, et al: Changes in the disc space after fractures of the thoracolumbar spine. J Bone Joint Surg Br 80:833-839, 1998

43. Parker JW, Lane JR, Karaikovic EE, et al: Successful short-segment instrumentation and fusion for thoracolumbar spine fractures: a consecutive 41/2-year series. Spine 25:1157-1170, 2000

44. Sanderson PL, Fraser RD, Hall DJ, et al: Short segment fixation of thoracolumbar burst fractures without fusion. Eur Spine J 8: 495-500, 1999

45. Shen WJ, Liu TJ, Shen YS: Nonoperative treatment versus posterior fixation for thoracolumbar junction burst fractures without neurologic deficit. Spine 26:1038-1045, 2001

46. Sjostrom L, Jakobsson O, Karlstrom G, et al: Transpedicular bone grafts misplaced into the spinal canal. J Orthop Trauma 6:376-378, 1992

47. Speth MJ, Oner FC, Kadic MA, et al: Recurrent kyphosis after posterior stabilization of thoracolumbar fractures. 24 cases treated with a Dick internal fixator followed for 1.5-4 years. Acta Orthop Scand 66:406-410, 1995

48. Theodorou DJ, Theodorou SJ, Duncan TD, et al: Percutaneous balloon kyphoplasty for the correction of spinal deformity in painful vertebral body compression fractures. Clin Imaging 26:1-5, 2002

49. Tomita S, Molloy S, Jasper LE, et al: Biomechanical comparison of kyphoplasty with different bone cements. Spine 29: 1203-1207, 2004

50. Truumees E, Hilibrand A, Vaccaro AR: Percutaneous vertebral augmentation. Spine J 4:218-229, 2004

51. Verlaan JJ, van Helden WH, Oner FC, et al: Balloon vertebroplasty with calcium phosphate cement augmentation for direct restoration of traumatic thoracolumbar vertebral fractures. Spine 27:543-548, 2002

Manuscript received January 18, 2005.

Accepted in final form February 17, 2005.

Address reprint requests to: Christopher P. Ames, M.D., Department of Neurological Surgery, University of California, San Francisco, 505 Parnassus Avenue, Moffitt Hospital M779, Box 0112, San Francisco, California 94143. email: amesc@ neurosurg.ucsf. edu. 